\title{
Procalcitonin Identifies Bacterial Coinfections in Vietnamese Children with Severe Respiratory Syncytial Virus Pneumonia
}

\author{
Quyet Do, ${ }^{1}$ Tuan Minh Dao, ${ }^{2}$ Tran Ngoc Thi Nguyen $\mathbb{D}^{2}{ }^{2}$ Quynh Anh Tran, ${ }^{3}$ \\ Hau Thi Nguyen, ${ }^{2}$ and Tam Thi Ngo $\mathbb{1}^{4}$ \\ ${ }^{1}$ Respiratory Department, Military Medical Academy, Hanoi, Vietnam \\ ${ }^{2}$ Respiratory Department, National Children's Hospital, Hanoi, Vietnam \\ ${ }^{3}$ Surgical Department, National Children's Hospital, Hanoi, Vietnam \\ ${ }^{4}$ Faculty of Health Sciences, Thang Long University, Hanoi, Vietnam
}

Correspondence should be addressed to Tran Ngoc Thi Nguyen; dr.ngoctran259@yahoo.com.vn

Received 2 December 2019; Revised 23 March 2020; Accepted 11 April 2020; Published 9 May 2020

Academic Editor: Shin-ichi Yokota

Copyright $\odot 2020$ Quyet Do et al. This is an open access article distributed under the Creative Commons Attribution License, which permits unrestricted use, distribution, and reproduction in any medium, provided the original work is properly cited.

This study assessed the diagnostic value of interleukin- (IL-) 6, high-sensitivity C-reactive protein (hs-CRP), and procalcitonin (PCT) in differentiating severe pneumonia caused by respiratory syncytial virus (RSV) alone and RSV with bacterial coinfections among Vietnamese children under 5 years old. A cross-sectional study on 70 children with severe RSV pneumonia was conducted. IL-6, hs-CRP, and PCT tests were performed. Receiver operating characteristic (ROC) analysis was employed to measure the diagnostic values of PCT, IL-6, and hs-CRP. Of 70 children, 11 children were confirmed to have bacterial coinfections. The most common bacterial coinfection was Haemophilus influenzae. This study underlined that inflammatory biomarkers such as PCT had a moderate-to-high capability of disseminating severe pneumonia children with RSV alone or RSV and bacterial coinfections. This may support clinicians in administrating appropriate antibiotics to children suffering from severe RSV pneumonia.

\section{Introduction}

Respiratory syncytial virus (RSV) is well recorded as a leading cause of lower respiratory tract infection (LRTI) in infants under 1 year old. RSV is annually attributable to 34 million LRTI episodes, accounting for $80 \%$ of LRTI cases globally $[1,2]$. Moreover, this virus causes approximately 200,000 deaths among children aged less than five years, which mostly happened in resource-constrained countries [1].

Evidently, bacterial coinfections could elevate the severity of pneumonia in children compared to viral infections alone [3-5]. However, regular laboratory tests and radiographic results have poor ability to differentiate viral pneumonia patients with or without bacterial coinfections [6-8]. Thus, identifying biology markers to early and effectively discriminate these two circumstances is necessary for deciding whether antibiotics should be used or not. To date, some inflammatory biomarkers such as interleukin- (IL-) 6, high- sensitivity C-reactive protein (hs-CRP), and more recently, procalcitonin (PCT) are widely mentioned as potential mediators for diagnosing inflammatory illnesses $[9,10,20]$. PCT has been used in several guidelines to manage antibiotic use in children with respiratory diseases $[11,12]$ because a high level of serum PCT concentration frequently occurs in those with bacterial or parasitic infections [13].

This study is aimed at assessing the diagnostic value of hs-CRP, PCT, and IL-6 in differentiating severe pneumonia caused by RSV alone and RSV with bacterial coinfections among Vietnamese children under 5 years old.

\section{Materials and Methods}

2.1. Study Designs. We performed a cross-sectional study in 70 children who were confirmedly diagnosed with severe RSV pneumonia treated at the National Hospital of Paediatrics from January 2015 to March 2017 according to WHO 
2013 standards [14]. Severe cases of pneumonia were defined when having a cough or difficulty in breathing plus at least one of the following main symptoms: (1) cyanosis or $\mathrm{SpO}_{2}<90 \%$, (2) severe respiratory distress (moaning and intercostal muscle external retraction), (3) could not drink or give up or vomit everything, coma or not awake, or convulsions. We excluded children who (1) were under 1 month of age and older than 5 years, (2) had non-RSV pneumonia (for example, pneumonia due to other viruses, pneumonia after drowning, chemical pneumonia, and aspiration pneumonia), (3) had chronic, associated congenital diseases (for example, airway malformation, congenital lung disease, liver failure, or kidney failure), (4) were coinfected with other viruses, and (5) were eligible to participate in the study but the parents or guardian did not agree to participate. The protocol of this study was approved by the institutional review board of Vietnam Military Medical University (Code 92/QD-HVQY).

2.2. Measurement. All patients after hospitalization were carefully examined for clinical symptoms by pediatrics. Their parents or guardians were also asked to collect information about demographic characteristics and history of illness. Two milliliters of blood samples was collected and centrifugated for biochemical tests. hs-CRP quantification was determined by turbidity measurement using Olympus AU 2700 machine. PCT quantification was measured by the luminescent immunization method, running on ADVIA Centaur of Siemens. Specimens were put into tubes without anticoagulants or with Li-Heparin and K3-EDTA anticoagulants. After collecting blood samples, they were centrifugated to extract serum or plasma. Meanwhile, IL- 6 was quantified with the Bio-Plex Protein Array System of Bio-Rad.

Bacterial testing was performed by the Vitek 2 machine. The colorimetric method was used to identify the chemical biological properties of bacteria by changing the color of environmental wells. Moreover, an antibiogram method was applied using MIC (minimum inhibitory concentration) in order to measure turbidity which can monitor the development of microorganisms in the environmental wells. These two methods were performed according to the principle of light intensity reduction: the optical system used visible light to directly monitor the growth of microorganisms through the measurement of the intensity of the blocked light (or attenuation of light intensity) when light passes through a well. The system used $660 \mathrm{~nm}, 568 \mathrm{~nm}$, and $428 \mathrm{~nm}$ wavelengths.

2.3. Statistical Analysis. Clinical and laboratory characteristics were compared between severe pneumonia children with RSV alone and RSV with bacterial coinfections by using Student's $t$-test (for age, respiratory rate, pulse rate, body temperature, and $\mathrm{SpO}_{2}$ ), Mann-Whitney test (white blood cells, lymphocyte, procalcitonin, high-sensitivity C-reactive protein, $\mathrm{PaO}_{2}$, and interleukin-6), and Chi-squared test (for gender, clinical features, and deaths after hospitalization). Receiver operating characteristic (ROC) analysis was employed to measure the diagnostic values of PCT, IL-6, and hs-CRP. This analysis informed some indices to measure the diagnostic accuracy including area under the ROC curve, sensitivity, specificity, positive predictive value (PPV), negative predic-

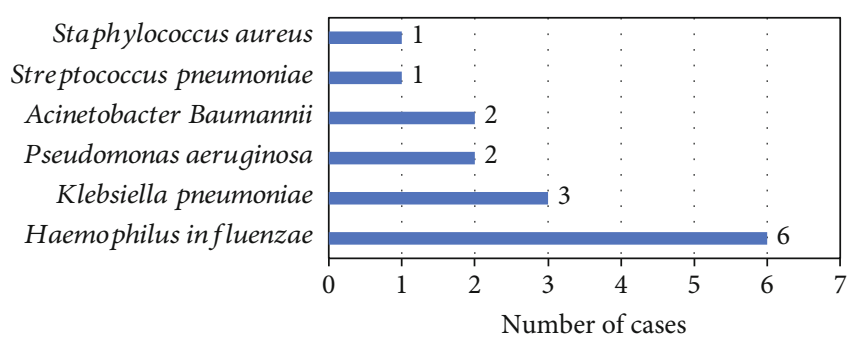

FIGURE 1: Distribution of bacterial pathogens in RSV pneumonia children with bacterial coinfections.

tive value (NPV), positive likelihood ratio $(\mathrm{LR}+)$, negative likelihood ratio (LR-), and accuracy rate. Youden index was calculated to identify the optimal cut-off point. STATA software 12.0 was used to analyze data. A two-tailed $p$ value of less than 0.05 was considered statistically significant.

\section{Results}

Of 70 children diagnosed with severe RSV pneumonia during the study period, 11 children were confirmed to have bacterial coinfections (15.7\%). The most common bacterial coinfection was Haemophilus influenzae (6 cases), followed by Klebsiella pneumoniae (3 cases) and Pseudomonas aeruginosa (2 cases) (Figure 1).

The mean age of patients was $5.8(\mathrm{SD}=8.2)$ months; $51.4 \%$ were males. There were two children that died after hospitalization (2.9\%). The median of PCT was 0.3 (IQR = $0.12-1.2) \mathrm{ng} / \mathrm{ml}$, the median of hs-CRP was $1.8(\mathrm{IQR}=0.66$ -6.2) $\mathrm{mg} / \mathrm{dl}$, and the median of white blood cells was 9.7 $(\mathrm{IQR}=7.05-12.6) \mathrm{g} / \mathrm{dl}$. Table 1 shows the demographic, clinical, and laboratory characteristics of RSV pneumonia patients. Patients with coinfections had a significantly higher proportion of fever, higher body temperature, PCT, hs-CRP, and a higher proportion of deaths after hospitalization compared to those with RSV alone $(p<0.05)$.

Figure 2 illustrates the distribution of PCT, hs-CRP, and IL- 6 between severe pneumonia children with RSV alone and RSV combined with bacterial coinfections.

Results of receiver operating characteristics (ROC) curve analysis are shown in Figure 3. Overall, the area under curve was 0.749 (95\%confidence interval $=0.571-0.927, p=0.006$ ) for PCT, 0.701 (95\%confidence interval $=0.521-0.882, p=$ 0.03 ) for hs-CRP, and 0.703 (95\% confidence interval $=$ $0.439-0.968, p=0.13$ ) for IL-6. The differences among areas under the ROC curve for these three biomarkers were insignificant $(p>0.05)$.

Diagnostic values for PCT, hs-CRP, and IL-6 are presented in Table 2. Based on the Youden index, the optimal cut-off point for PCT was $>2.25 \mathrm{ng} / \mathrm{ml}$ (sensitivity 55\%, specificity $92 \%$, positive predictive value $55 \%$, and negative predictive value $92 \%)$. The optimal cut-off point for hs-CRP was $>4.5 \mathrm{mg} / \mathrm{dl}$ (sensitivity $64 \%$, specificity $73 \%$, positive predictive value $30 \%$, and negative predictive value $92 \%$ ). Finally, the optimal cut-off point for IL-6 was $>10.68 \mathrm{pg} / \mathrm{ml}$ (sensitivity $63 \%$, specificity $85 \%$, positive predictive value $42 \%$, and negative predictive value $93 \%$ ). The most accurate was for PCT with $83.6 \%$, followed by IL-6 with $71.2 \%$. 
TABLE 1: Patients' characteristics between patients with RSV pneumonia alone and RSV pneumonia with bacterial coinfections.

\begin{tabular}{|c|c|c|c|}
\hline & RSV alone $(n=59)$ & RSV with bacterial coinfections $(n=11)$ & $p$ value \\
\hline Age (months) (mean $\pm \mathrm{SD})$ & $5.6 \pm 8.5$ & $6.8 \pm 6.5$ & 0.67 \\
\hline Male, $n(\%)$ & $29(49.2)$ & $7(63.6)$ & 0.38 \\
\hline \multicolumn{4}{|l|}{ Clinical features } \\
\hline Fever & $22(37.3)$ & $9(81.8)$ & $<0.01$ \\
\hline Rapid pulse rate & $32(54.2)$ & $6(54.6)$ & 0.99 \\
\hline Runny nose & $16(27.1)$ & $3(27.3)$ & 0.99 \\
\hline Wheezing & $53(89.8)$ & $9(81.8)$ & 0.44 \\
\hline Diarrhea & $14(23.7)$ & $2(18.2)$ & 0.69 \\
\hline \multicolumn{4}{|l|}{ Vital signs $($ mean $\pm S D)$} \\
\hline Respiratory rate (/min) & $54.5 \pm 7.2$ & $54.1 \pm 9.3$ & 0.87 \\
\hline Pulse rate $(/ \mathrm{min})$ & $153.3 \pm 18.5$ & $154.6 \pm 21.5$ & 0.83 \\
\hline Body temperature $\left({ }^{\circ} \mathrm{C}\right)$ & $37.3 \pm 0.8$ & $38.6 \pm 1.0$ & $<0.01$ \\
\hline $\mathrm{SpO}_{2}$ & $88.5 \pm 4.6$ & $88.2 \pm 4.0$ & 0.82 \\
\hline \multicolumn{4}{|l|}{ Initial laboratory findings (median, IQR) } \\
\hline WBC $\left(\times 10^{3} / \mathrm{mm}^{3}\right)$ & $9.5(7.1-12.1)$ & $11.2(5.4-17.3)$ & 0.62 \\
\hline Lymphocyte (\%) & $4.6(2.9-6.3)$ & $3.4(2.2-9.0)$ & 0.46 \\
\hline Procalcitonin (ng/ml) & $0.3(0.1-1.1)$ & $2.3(0.2-4.2)$ & $<0.01$ \\
\hline High-sensitivity C-reactive protein (mg/dl) & $1.5(0.6-4.9)$ & $5.7(1.7-23.6)$ & 0.04 \\
\hline $\mathrm{PaO}_{2}$ & $69.0(50.0-82.0)$ & $64.9(54.0-92.0)$ & 0.99 \\
\hline Interleukin-6 (pg/ml) & $2.0(1.5-6.1)$ & $12.4(3.0-82.8)$ & 0.07 \\
\hline Deaths after hospitalization, $n(\%)$ & $0(0.0)$ & $2(18.2)$ & $<0.01$ \\
\hline
\end{tabular}

SD: standard deviation; $\mathrm{SpO}_{2}$ : oxygen saturation; WBC: white blood cell.

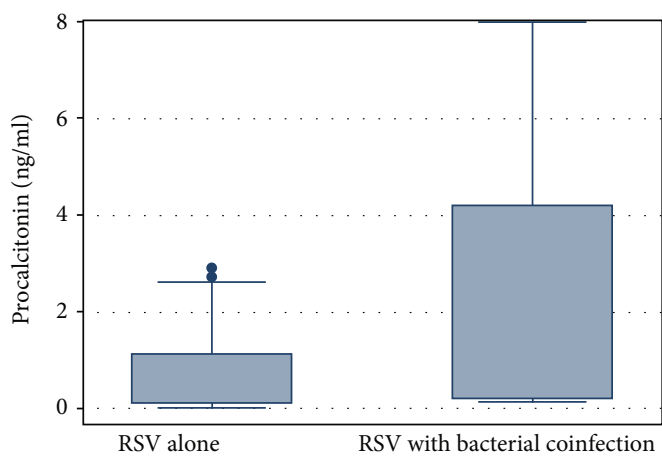

(a)

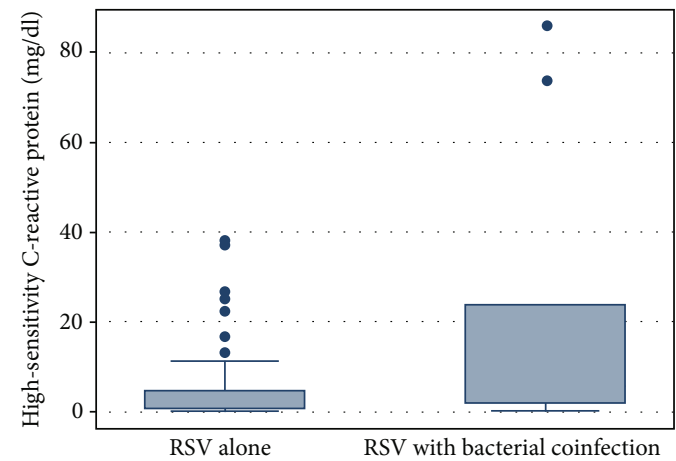

(b)

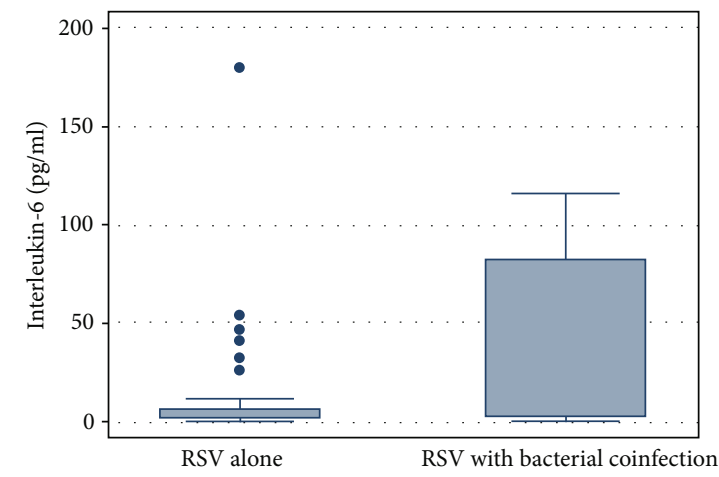

(c)

FIGURE 2: Box plot of (a) procalcitonin (PCT), (b) high-sensitivity C-reactive protein (hs-CRP), and (c) interleukin-6 (IL-6) levels on initial hospital visit between RSV pneumonia alone and RSV pneumonia with bacterial coinfections. 


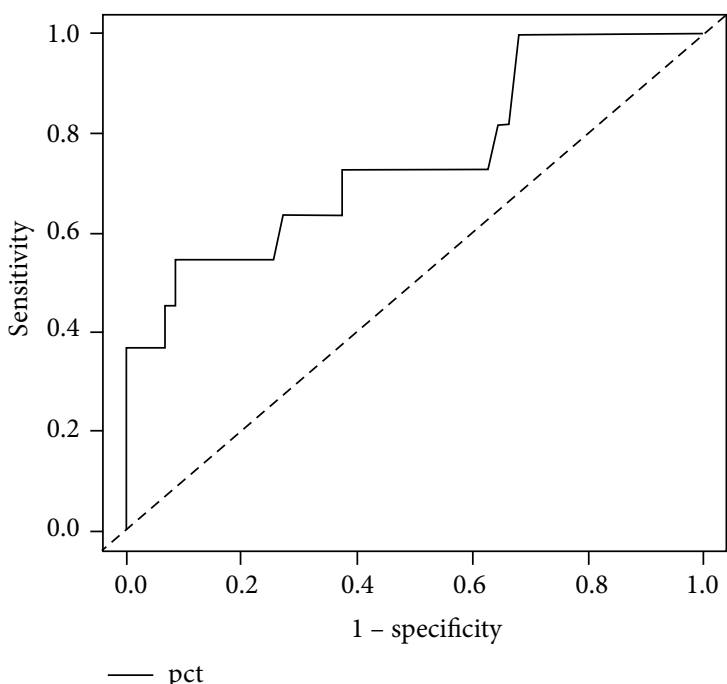

(a)

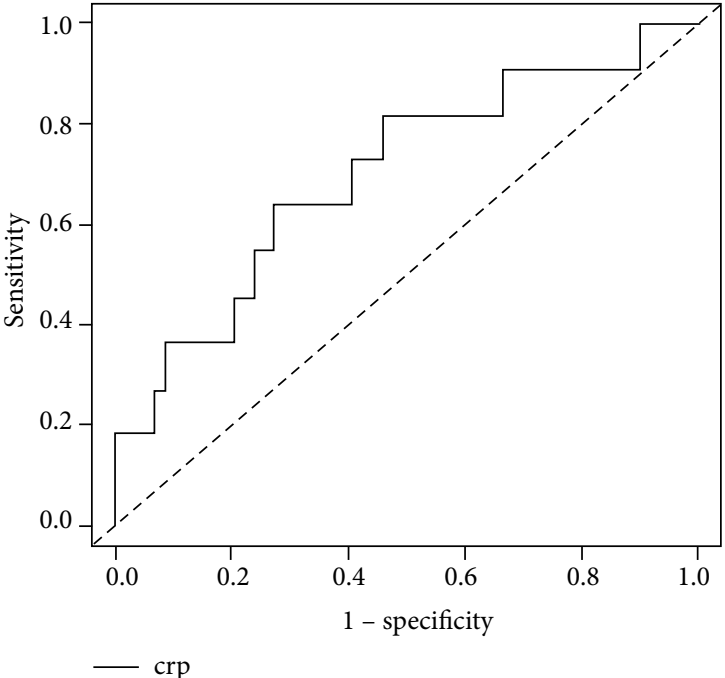

(b)

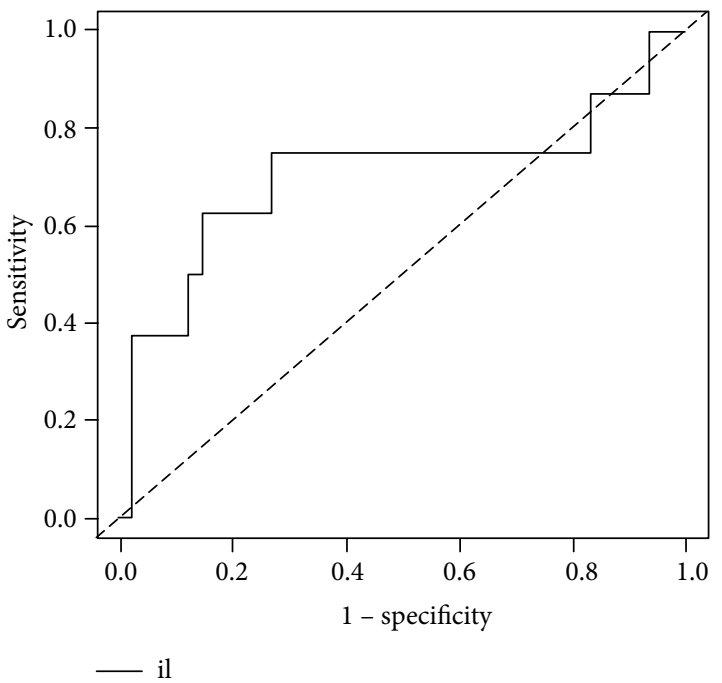

(c)

FIGURE 3: Receiver operating characteristics curve for discriminating between RSV pneumonia alone and RSV pneumonia with coinfections for (a) procalcitonin (PCT), (b) high-sensitivity C-reactive protein (hs-CRP), and (c) interleukin-6 (IL-6) on the initial hospital visit.

TABLE 2: Accuracy of diagnostic parameters regarding different cut-off points.

\begin{tabular}{lccccc}
\hline & PCT $>0.5 \mathrm{ng} / \mathrm{ml}$ & PCT $>2.25 \mathrm{ng} / \mathrm{ml}$ & $\mathrm{IL}-6>10.68 \mathrm{pg} / \mathrm{ml}$ & $\mathrm{IL}-6>100 \mathrm{pg} / \mathrm{ml}$ & $\mathrm{hs}-\mathrm{CRP}>4.5 \mathrm{mg} / \mathrm{dl}$ \\
\hline Sensitivity & $0.73(0.39-0.94)$ & $0.55(0.23-0.83)$ & $0.63(0.25-0.92)$ & $0.25(0.03-0.65)$ & $0.64(0.31-0.89)$ \\
Specificity & $0.63(0.49-0.75)$ & $0.92(0.81-0.97)$ & $0.85(0.72-0.94)$ & $0.98(0.89-1.00)$ & $0.73(0.60-0.84)$ \\
Positive predictive value (PPV) & $0.28(0.17-0.68)$ & $0.55(0.33-0.83)$ & $0.42(0.15-0.72)$ & $0.67(0.26-0.92)$ & $0.30(0.19-0.67)$ \\
Negative predictive value (NPV) & $0.93(0.75-0.96)$ & $0.92(0.73-0.97)$ & $0.93(0.81-0.99)$ & $0.89(0.44-1.00)$ & $0.92(0.73-0.95)$ \\
Positive likelihood ratio (LR+) & $1.95(1.19-3.19)$ & $6.44(2.38-17.45)$ & $4.29(1.80-10.20)$ & $12.00(1.23-117.41)$ & $2.35(1.27-4.33)$ \\
Negative likelihood ratio (LR-) & $0.44(0.16-1.16)$ & $0.50(0.26-0.95)$ & $0.44(0.18-1.08)$ & $0.77(0.51-1.15)$ & $0.50(0.23-1.11)$ \\
Accuracy & $64.3 \%$ & $84.3 \%$ & $82.1 \%$ & $87.5 \%$ & $70.0 \%$ \\
\hline
\end{tabular}

PCT: procalcitonin; hs-CRP: high-sensitivity C-reactive protein; IL-6: interleukin-6.

\section{Discussion}

Identifying biomarkers for the rapid detection of bacterial coinfections in RSV pneumonia among children hospitalized is essential in emergency circumstances. Our study highlights the potential role of serum PCT concentration in detecting and discriminating children with severe RSV pneumonia alone and severe RSV pneumonia with bacterial coinfections.

In this study, the optimal cut-off point for PCT was $2.25 \mathrm{ng} / \mathrm{ml}$, which might be different from prior studies using 
PCT to discriminate these two types of patients in respiratory diseases. A study of Ahn et al. showed that PCT $>1.5 \mathrm{ng} / \mathrm{ml}$ had sensitivity $56 \%$ and specificity $84 \%$ to detect pneumonia patients having mixed bacterial coinfection or not [15]. Other studies by Chirouze et al. in patients with acute fever [16], Ingram et al. in H1N1 influenza patients [17], and Chua and Lee in severe acute respiratory syndrome [18] indicated the cut-off point for PCT was $0.4 \mathrm{ng} / \mathrm{ml}, 0.8 \mathrm{ng} / \mathrm{ml}$, and $1.0 \mathrm{ng} / \mathrm{ml}$, respectively. These variances might be attributable to the presence of different viruses and bacteria in each study. Moreover, our study employed children who suffered from severe RSV pneumonia, who actually had a high level of PCT compared to samples in other studies who had a variety of levels of disease severity.

In literature, serum PCT, hs-CRP, and IL-6 concentration have been used widely to differentiate patients suffering viral respiratory diseases alone and those with bacterial coinfections $[9,10,20]$. Most of the studies found that PCT was dominant in differentiating viral and bacterial infections compared to hs-CRP and IL-6 [9, 10, 19, 20]. Our finding in this study was in line with these previous works when we found that the accuracy rate of PCT was higher than that of IL- 6 and hs-CRP. In addition, clinical symptoms and other laboratory test measures were not sufficient for diagnosing bacterial coinfections, which aligned with previous findings [6-8]. Serum PCT concentration above $2.25 \mathrm{ng} / \mathrm{ml}$ could detect bacterial coinfections more effectively, which can be applied in emergency cases. However, Laham et al. [20] and Baer et al. [21] found that some infants with pneumonia did not detect bacterial coinfections even when they had the highest value of PCT. This result was similar to another study in severe acute respiratory syndrome caused by SARS-CoV-2 virus [22] which suggested that antibiotic use might not be necessary for patients with high PCT. Therefore, in order to use antibiotic appropriately, further tests to confirm the existence of bacterial coinfection should be performed. Nonetheless, although PCT alone cannot be used to decide which antibiotics should be utilized, this is a vital marker that clinicians should require when making a decision rather than based on radiographic or blood cell count findings. Therefore, developing a rapid bedside PCT test is crucial in managing children experiencing severe RSV pneumonia.

This study contained several limitations. First, our sample size was small and conveniently recruited, which thus might reduce our generalizability. Second, our crosssectional design has its own limitations due to its nature. Several recent studies argued that making decisions related to antibiotic use should use data of serum PCT concentration overtime via a longitudinal cohort rather than using the initial PCT level $[23,24]$. In Vietnam, the PCT test has been covered in the health insurance scheme, which facilitates the use of PCT in routine monitoring and controlling bacteria in children with severe RSV pneumonia.

\section{Conclusions}

This study underlined that inflammatory biomarkers such as PCT had a moderate-to-high capability to disseminate severe pneumonia children with RSV alone or RSV and bacterial coinfections. This may support clinicians in administrating appropriate antibiotics to children suffering from severe RSV pneumonia.

\section{Data Availability}

The data used to support the findings of this study are available from the corresponding author. Requests for access to individual subject data may be made to Tran Ngoc Thi Nguyen, email dr.ngoctran259@yahoo.com.vn

\section{Conflicts of Interest}

The authors declare that they have no conflicts of interest.

\section{References}

[1] H. Nair, D. J. Nokes, B. D. Gessner et al., "Global burden of acute lower respiratory infections due to respiratory syncytial virus in young children: a systematic review and meta-analysis," The Lancet, vol. 375, no. 9725, pp. 1545-1555, 2010.

[2] G. Piedimonte, "RSV infections: state of the art," Cleveland Clinic Journal of Medicine, vol. 82, pp. S13-S18, 2015.

[3] O. Ruuskanen, E. Lahti, L. C. Jennings, and D. R. Murdoch, "Viral pneumonia," The Lancet, vol. 377, no. 9773, pp. 12641275, 2011.

[4] B. M. W. Diederen, M. M. Eerden, F. Vlaspolder, W. G. Boersma, J. A. J. W. Kluytmans, and M. F. Peeters, "Detection of respiratory viruses and Legionella spp by real-time polymerase chain reaction in patients with community acquired pneumonia," Scandinavian Journal of Infectious Diseases, vol. 41, no. 1, pp. 45-50, 2009.

[5] L. C. Jennings, T. P. Anderson, K. A. Beynon et al., "Incidence and characteristics of viral community-acquired pneumonia in adults," Thorax, vol. 63, no. 1, pp. 42-48, 2008.

[6] D. Gendrel, J. Raymond, F. Moulin et al., "Etiology and response to antibiotic therapy of community-acquired pneumonia in French children," European Journal of Clinical Microbiology \& Infectious Diseases, vol. 16, no. 5, pp. 388391, 1997.

[7] H. Peltola and M. Jaakkola, "C-reactive protein in early detection of bacteremic versus viral infections in immunocompetent and compromised children," The Journal of Pediatrics, vol. 113, no. 4, pp. 641-646, 1988.

[8] P. Ashorn, "Bacteremic pneumococcal pneumonia in children," Clinical Infectious Diseases, vol. 29, no. 3, pp. 568-572, 1999.

[9] A. G. Lacour, A. Gervaix, S. A. Zamora et al., "Procalcitonin, IL-6, IL-8, IL-1 receptor antagonist and C-reactive protein as identificators of serious bacterial infections in children with fever without localising signs," European Journal of Pediatrics, vol. 160, no. 2, pp. 95-100, 2001.

[10] L. Simon, F. Gauvin, D. K. Amre, P. Saint-Louis, and J. Lacroix, "Serum procalcitonin and C-reactive protein levels as markers of bacterial infection: a systematic review and meta-analysis," Clinical Infectious Diseases, vol. 39, no. 2, pp. 206-217, 2004.

[11] A. Kumar, P. K. Debata, A. Ranjan, and R. Gaind, "The role and reliability of rapid bedside diagnostic test in early diagnosis and treatment of bacterial meningitis," The Indian Journal of Pediatrics, vol. 82, no. 4, pp. 311-314, 2015. 
[12] D. Stolz, M. Christ-Crain, R. Bingisser et al., "Antibiotic treatment of exacerbations of COPD: a randomized, controlled trial comparing procalcitonin-guidance with standard therapy," Chest, vol. 131, no. 1, pp. 9-19, 2007.

[13] M. Assicot, C. Bohuon, D. Gendrel, J. Raymond, H. Carsin, and J. Guilbaud, "High serum procalcitonin concentrations in patients with sepsis and infection," The Lancet, vol. 341, no. 8844, pp. 515-518, 1993.

[14] WHO, Guidelines for the Management of Common Childhood Illnesses, 2nd edition2nd edition, , 2013.

[15] S. Ahn, W. Y. Kim, S. H. Kim et al., "Role of procalcitonin and C-reactive protein in differentiation of mixed bacterial infection from 2009 H1N1 viral pneumonia," Influenza and Other Respiratory Viruses, vol. 5, no. 6, pp. 398-403, 2011.

[16] C. Chirouze, H. Schuhmacher, C. Rabaud et al., "Low serum procalcitonin level accurately predicts the absence of bacteremia in adult patients with acute fever," Clinical Infectious Diseases, vol. 35, no. 2, pp. 156-161, 2002.

[17] P. R. Ingram, T. Inglis, D. Moxon, and D. Speers, "Procalcitonin and C-reactive protein in severe $2009 \mathrm{H} 1 \mathrm{~N} 1$ influenza infection," Intensive Care Medicine, vol. 36, no. 3, pp. 528532, 2010.

[18] A. P. Chua and K. H. Lee, "Procalcitonin in severe acute respiratory syndrome (SARS)," Journal of Infection, vol. 48, no. 4, pp. 303-306, 2004.

[19] F. Moulin, J. Raymond, M. Lorrot et al., "Procalcitonin in children admitted to hospital with community acquired pneumonia," Archives of Disease in Childhood, vol. 84, no. 4, pp. 332-336, 2001.

[20] J. L. Laham, P. J. Breheny, B. M. Gardner, and H. Bada, "Procalcitonin to predict bacterial coinfection in infants with acute bronchiolitis: a preliminary analysis," Pediatric Emergency Care, vol. 30, no. 1, pp. 11-15, 2014.

[21] G. Baer, P. Baumann, M. Buettcher et al., "Procalcitonin guidance to reduce antibiotic treatment of lower respiratory tract infection in children and adolescents (ProPAED): a randomized controlled trial," PLoS ONE, vol. 8, no. 8, 2013.

[22] C. Huang, Y. Wang, X. Li et al., "Clinical features of patients infected with 2019 novel coronavirus in Wuhan, China," The Lancet, vol. 395, no. 10223, pp. 497-506, 2020.

[23] N. Boussekey, O. Leroy, S. Alfandari, P. Devos, H. Georges, and B. Guery, "Procalcitonin kinetics in the prognosis of severe community-acquired pneumonia," Intensive Care Medicine, vol. 32, no. 3, pp. 469-472, 2006.

[24] M. Christ-Crain, D. Stolz, R. Bingisser et al., "Procalcitonin guidance of antibiotic therapy in community-acquired pneumonia: a randomized trial," American Journal of Respiratory and Critical Care Medicine, vol. 174, no. 1, pp. 84-93, 2006. 